\title{
The Impacts of Social Media on Political Communication: a Case Study of News on Chinese Officials' Corruption
}

\author{
Wenzhe Zhu ${ }^{1}$ \\ ${ }^{1}$ School of Journalism \& Communication, Jinan University, Guangzhou, Guangdong Province, China
}

Keywords: Social Media, Political Communication, Social Mobilization.

\begin{abstract}
In recent years, social media develops rapidly in China, and changes the traditional media pattern in this new era of information. Due to the widespread of social media, ordinary Chinese people now have different ways to take part in political events. Social media has become the platform of political participation and social governance for ordinary people. In this paper, news on corrupt officials is taken as an example to study the impacts of social media on political communication from the perspective of political communication. Then social media's initiative functions in the political communication, political participation and public opinion guidance are analyzed to confirm the strategic value of social media in political communication.
\end{abstract}

\section{Social Media Have Great Ability of Social Mobilization}

In the information era, the changes of media forms transform communication patterns. The widespread social media changes traditional media patterns, and brings new research topics to theory on political communication. Sex scandal is a topic which western media always take delight in talking about. News on unfaithful stars, clandestine love affairs of officials, and business tycoons who always chasing beauties are quite common seen in western media. In China, however, based on culture tradition and media management system, traditional media include newspapers, radio and television programs always adhere to the principle of positive guidance on public opinion; tidbits rarely appears in traditional Chinese media. Punishment reports can be found when the parties involved have been punished.

Social media can disseminate contents produced by users. Without editors' evaluation, messages on improper sexual relations of officials spread quickly. Under the social background of comprehensive transformation of China, corruption of government officials and imbalance interest distribution mechanism accumulate large number of social contradictions. The public are ready to use social media as a platform to expose corruption and uphold justice. They expose, forward and comment related information, and thus form a kind of network crowd behavior. News on improper sexual relationships of government officials arouses public concern and indignation from time to time. "Micro-blog anti-corruption", "mistress anti-corruption" have become hot words on the network. A research report points out that 95\% Chinese corrupt officials have mistress. Sex scandal has become the most short safety fuse for officials' downfall. Widespread messages on scandal official on social media not only discredit the image of public servant, but also highlight social media's power in information dissemination, challenge traditional political communication pattern, and highlight the public communication demands as well as social media's potential in social mobilization.

\section{Traditional Political Communication Pattern Undergoes Profound Changes}

From the traditional point of view, political communication promotes communication process through the dissemination of political information through various channels and the use of various symbols to influence audiences' attitudes and behaviors. [1] In the era of traditional media, political communication cannot avoid the disadvantages of persuasion and one-way indoctrination. Through media checks and agenda setting, all information disseminated on mass media is politically correct. The decentralization characteristic of social media changes this political communication mode. The general public is actively involved in the communication process as information source and medium, thus become the body of political communication. The public and the government can interact with 
each other on social media instantly, while general citizens can express their political appeals through social media. [2] Social media offer more expression rights and supervision rights to users, thus improve the information rights and participation rights of the public to some extent. In the social media era, public opinion environment becomes more and more complicated and diversified. The single-way persuasion and inculcating political communication mode will not be able to continue.

Nowadays, social media has become the source of information release, and replaced the position of traditional media. Traditional media have been deprived from news interpretation rights. Taking Lei's event as an example: at the evening of November 20, 2012, micro-blog user named "Ji Xu Guang" claimed that "Zheng-fu Lei, Chongqing Beibei District Secretary keeps mistress and has licentious life" and released a "sex video screen shot". The micro-blog became a hot topic instantly. At the same time, related video which is only about 36 seconds long was spread widely on the Internet, promoted the issue to become a focus event. Traditional media began to follow up the report. Three days later, Lei was removed from office and accepted investigation. During this process, the user kept releasing information through micro-blog, blogs and other social media, and communicated with government departments. Traditional media reports followed his steps. The improper sexual relation of this official caused widespread concern in society; public opinion forced the discipline inspection departments to intervene as soon as possible. Since the exposure of sex video, it only takes 63 hours to investigate and dismiss this official. [3] Social media has become an important field of public opinion. The entrance of information dissemination is dispersed. The power of interpreting news events are no longer confined to traditional media organizations. Social media has changed the media ecology, and become an important field to publish information on social events and promote the development of social governance.

Social media has also become an important force in agenda setting, which plays an increasingly important role in the guidance of public opinion trend. Both agenda setting and the implementation of public policy are important forms for the government to implement public management functions. In the era of traditional media, Chinese government agencies implemented the management of media organizations through industry access and ownership system. Under the background of Web2.0, social media give users great autonomy rights. Users can disseminate information freely, which dilutes the traditional media's agenda setting to a certain extent. Many Internet users even no longer trust traditional media. Agenda setting of traditional media is faced by serious challenges. For news on officials who involved in improper sexual relations, it is difficult for traditional media to obtain valuable information. Insiders who break the news often hold a lot of photos, videos or even check in records. Traditional media have to follow their steps, when the social media implement agenda setting function. In this case, in order to adapt to new rules, traditional media need to imitate social media from content to form, which further enhances the status of social media in the dissemination pattern. The new media ecology evolves in the game; the new generation communication center forms in the evolution; social media and the public replace the place of traditional media and social elites; interest groups become the key force who set political communication agenda and promote social development.

Social media is changing the serious preaching feature of traditional political communication. It promote political news reports to become relaxed, lively, close to the audiences' cognitive level, and more easy to communicate. In the past thirty years, profound changes have taken place in Chinese society and in people's aesthetic psychology. The preaching style uphold by traditional media is no longer accepted by the audience. Social media provides a changing opportunity for the serious, preaching mode. On one hand, users of social media are general public; the contents in dissemination must be accepted by them. On the other hand, social media has more grassroots attributes; they prefer simple expression methods. Social media has changed the moral superiority of traditional media. It promotes traditional media to carry out political communication through civilian, conversational style, and create a relaxed, friendly atmosphere in reports. At the same time, the transformation of traditional media also associates with adverse consequences. The over pursuit of sensory stimulation brings vulgar content, as well as sensational and entertainment reports. In numerous reports of corrupt officials, the media do not start from party discipline or keep ringing the alarm bell. Instead, they 
describe officials' improper sexual relations in detail, and ridicule the mistress phenomenon with entertainment words and pictures. The serious political issues of "discipline", "anti corruption" and "supervision" are all removed. Affected by Internet culture and entertainment news, political news show an inclination of entertainment, which has become a global cultural landscape. Frequent news on officials' improper sexual relations successfully draws public attentions to the private life of corrupt officials. It meets public's curiosity, but also avoids the value demands of political communication.

\section{Political Communication Should Adhere to the Position of Justice and Value Pursuit}

For a long time, the Chinese government attaches great importance to the ideological work. As an important functional organization, traditional media takes the task of promoting specific political philosophy. After the reform and opening up, Chinese society has entered a period of profound transformation. The interest bodies diversify; social structure differentiates; value demands become divided. The new social reality puts forward to new challenges to political communication. The emergence and widely usage of social media narrow the gap between media institutions and the public. Information technology provides ordinary people with "speakers". Social media has become the connection link of political system and social media, and the field of political interest game. [4] The influences of social media on politics are becoming more and more obvious. It is changing the mode of public participation, the discourse space of international politics and the active ability of individuals. Social media has become an important platform for Chinese citizens to take part in social communication and information dissemination. It resets the information flow of political communication, changes the functions of political communication in public areas, and become a social governance space for common people to participate in politics.

According to data from China Internet Network Information Center, as to December 2016, Chinese Internet users reached 731 million people. The huge accumulation of user means great communication potential. Especially through the corruption news exposed in social media, discontent and complain about the real life aggregate in social media, and show tremendous impacts on the old governance order. Traditional media and government credibility are facing severe challenge. Political communication implicates specific connotations for the effect of propogation, and thereby stipulates the functions of political agenda setting in the transmission of political information, the guidance of public opinion, the stimulation of political participation, the portrayal of government's image, and the promotion of media supervision. On one hand, it satisfies audiences' right to know, responds general public's calling for punishment against corruption. On the other hand, it demonstrates the mainstream ideology of government through social media, and achieves the goals of maintaining social stability and uniting the public. The practice of social media communication effectively expands the connotation, extension and paths of political communication. "Network anti-corruption", "micro-blog anti-corruption", "mistress anti-corruption" and other topics become focus events on social media from time to time. [5] When promoting the process of political civilization, we also need to prevent the disruption of normal order in information dissemination and interference of political communication effects.

Political communication is different from health communication or cultural dissemination. [6] It needs to adhere to correct political standpoint, have clear political demands, the dissemination of the contents of Ideological and political value attribution guide. At present, the media ecology is in the process of integration and development, and the status of new media is becoming more and more important. Having a profound understanding of the strategic value and role of social media in political communication, and making full use of social media and social mobilization resources to spread ruling ideas, promote social cohesion, and shape the image of the government and people, are of extremely important significance. At the same time, under the premise of maintaining the legitimacy of national production and reproduction, how to build social consensus needed by the development of modern society, how to cultivate Internet users' habits of orderly expression in virtual space of media, are political communication problems which need to be solved. 


\section{References}

[1] W. L. Bennett, R. M. Enteman. Mediated Politics: Communication in the Future of Democracy. Trans. G.P. Dong, Tsinghua University Press, Beijing, 2011

[2] M.S. Ren, Z.M. Zhu, On the political communication functions of social media in the Twitter revolution in Iran, J. Journal of International Communication. 9 (2009)

[3] J. Tang, Official Image Crisis Report, 2012. Social Sciences and Academic Press, Beijing, 2012

[4] China Internet Network Information Center, Thirty-ninth Statistics Report on Internet Development in China.

Http:/www.cnnic.net.cn/hlwfzyj/hlwxzbg/hlwtjbg/201701/P020170123364672657408.pdf

[5] J. Hu, Chinese style erotic anti-corruption: 90\% news comes from official circles. Guangzhou Daily, 2012-12-16.

[6] B. McNair, Introduction to Political Communication. Trans. Q. Yin. Xinhua Publishing House, Beijing, 2005. 